\title{
Psychotropic Drugs in Pregnancy
}

\author{
Amlan Kusum Jana MD, DPM \\ Assistant Professor; KPC Medical College \& Hospital; Kolkata \\ Email : amlankj@yahoo.com
}

\section{INTRODUCTION}

Psychiatrists often have to deal with the dilemma of whether or not to continue psychotropic medications in their patients during pregnancy. The fact that a relapse of symptoms arising out of discontinuation is often more dangerous than the usual response with violence, suicide presenting in higher rates (needless to say that harms the mother as well as the fetus) on the face of the risks of teratogenicity of almost all the drugs in offer make the situation no different from a double edged sword.

On the other hand the fertility rate among women suffering from schizophrenic and other severe and persistentpsychiatricdisorders(SPPDs)hasincreased since deinstitutionalization ${ }^{1,2}$ mainly because of their involvement in sexual activities and availability of SGAs which does not cause hyperprolactinemia (except risperidone) ${ }^{3}$. Things are different in relation to BAD. Women with bipolar disorder are typically in their teens and early 20s at onset of the illness, placing them at risk of mood episodes during childbearing age. The female reproductive cycle also introduces multifactorial complexities into the treatment of the disease. The course of recurrence is often severe and characterized by a relatively high frequency of rapid-cycling forms, mixed mania, and antidepressant-induced mania. The issue of whether bipolar disorder improves during pregnancy is controversial $^{4}$; however, pregnancy seems not to be protective for all bipolar women. Indeed, during the gestational period, risk of a relapse of the disorder does not decrease ${ }^{5}$. The other disorders would be no different. This review attempts to resolve the dilemma in treating the pregnant psychiatric patients as far as possible.

\section{PREGNANCY :}

\section{PHYSIOLOGICAL CHANGES}

- In the mother : delayed gastric emptying, increased mucus production, decreased acid secretion, increased extra and intravascular volume, decreased plasma protein concentration and decreased binding capacity of the albumin, induction of microsomal enzymes and increased renal plasma flow: all these lead to making requirements for DOSE INCREASE.

- In the fetus : there is a decrease in thickness of Nitabuch's membrane with progression of pregnancy with an immature BBB and partially efficient liver leading to an exaggerated and prolonged effect of drug.

- The amount of drug excreted through breast milk depends primarily on the drug. Milk has lower $\mathrm{pH}$ (6.8-7.3) than blood so the weak bases diffuse more quickly in the milk.

\section{RISKS OF PHARMACOTHERAPY}

Teratogenicity : The maximum risk is from $8^{\text {th }}$ week (organogenesis) to $16^{\text {th }}$ week (CNS maturation) and according to their capacity to damage the fetus (mainly in $8^{\text {th }}-16^{\text {th }}$ week) USFDA categorizes drugs into : 


\begin{tabular}{|c|c|c|}
\hline Category & Description & Examples \\
\hline $\mathrm{X}$ & $\begin{array}{l}\text { Studies in animals or humans have demonstrated fetal } \\
\text { abnormalities and/or there is positive evidence of human fetal } \\
\text { risk based on adverse reaction data from investigational or } \\
\text { marketing experience, and the risks involved in use of the drug } \\
\text { in pregnant women clearly outweigh potential benefits. }\end{array}$ & \\
\hline D & $\begin{array}{l}\text { There is positive evidence of human fetal risk based on adverse } \\
\text { reaction data from investigational or marketing experience or } \\
\text { studies in humans, but potential benefits may warrant use of } \\
\text { the drug in pregnant women despite potential risks. }\end{array}$ & $\begin{array}{c}\text { CHDZP, LI, DZM, } \\
\text { CBZ, SV }\end{array}$ \\
\hline C & $\begin{array}{l}\text { Animal reproduction studies have shown an adverse effect on the fetus } \\
\text { and there are no adequate and well-controlled studies in humans, but } \\
\text { potential benefits may warrant use of the drug in pregnant women } \\
\text { despite potential risks. }\end{array}$ & $\begin{array}{l}\text { Many antipsychotics, } \\
\text { THP, LZM, RSP, VNX }\end{array}$ \\
\hline B & $\begin{array}{l}\text { Animal reproduction studies have failed to demonstrate a risk to } \\
\text { the fetus and there are no adequate and well-controlled studies in } \\
\text { pregnant women OR Animal studies have shown an adverse effect, } \\
\text { but adequate and well-controlled studies in pregnant women have } \\
\text { failed to demonstrate a risk to the fetus in any trimester. }\end{array}$ & $\begin{array}{l}\text { PXT, BSP, ZPM, } \\
\text { Clozapine, ?NRT }\end{array}$ \\
\hline A & $\begin{array}{l}\text { Adequateand well-controlled studieshavefailed todemonstrate } \\
\text { a risk to the fetus in the first trimester of pregnancy (and there } \\
\text { is no evidence of risk in later trimesters). }\end{array}$ & \\
\hline
\end{tabular}

Direct Neonatal Toxicity : Physical and behavioural symptoms. Incidence is low.

Behavioural teratogenesis : Developmental delays / neurodeficits.

Risks to mother : Changes in physiology leads to increased chances of toxicity for protein bound drugs as the unbound fraction increases.

\section{PSYCHOTROPIC DRUGS AND THEIR EFFECTS : SGAS}

Amisulpride : Australian Drug Evaluation Committee (ADEC) rates this as B3 (drugs which have been taken by only a limited number of pregnant women and women of childbearing age, with no increase in the frequency of malformation).
Despite there being no evidence of teratogenicity in embryo-fetal developmental studies in mice and rabbits following oral doses up to 4 times the maximum recommended human dose, no published information on human pregnancies is available. ${ }^{3}$

Aripiprazole : Aripiprazole is rated FDA Pregnancy Category C. There have been 3 case reports on fetal exposure to this drug with maximum effect being transient symptoms attributable to poor neonatal adaptation phenomena ${ }^{6,7}$ though in other 2 cases reporting no adverse effects, the exposure was at $20^{\text {th }}$ week.

Clozapine : Clozapine is rated FDA Pregnancy Category B, despite paucity of data. Reproductive studies performed in rats and rabbits at doses of approximately 2-4 times the human dose 
revealed no harm to the fetus. Single cases of major malformations (ASD, anal atresia etc), gestational metabolic complications, poor pregnancy outcome, and perinatal adverse reactions associated with exposure to clozapine during various stages of pregnancy have been subsequently reported, though they derive solely from case reports and/or small case series studies. However, clozapine overdose during pregnancy may cause fatal poisoning of the newborn ${ }^{8}$.

Olanzapine : Olanzapine is rated FDA Pregnancy Category C. Reproductive studies show no evidence of fetal harm in animals. Sporadic cases of olanzapine-associated fetal major malformations, gestational metabolic complications (such as the onset or worsening of gestational diabetes), neonatal adverse reactions, self-remitted neurodevelopmental impairment (e.g. meningocele and complete ankyloblepharon, hip dysplasia, aqueductal stenosis etc) are now being recorded ${ }^{9,10}$. Newport et al $(2007)^{11}$ investigated the placental passage (defined as the ratio between umbilical cord and maternal plasma concentrations) of different antipsychotic agents. Olanzapine showed a higher amount of placental passage (mean $72.1 \%, \mathrm{SD}=42.0 \%$ ) and, also, higher rates of either low birth weight and/ or perinatal complications as compared with other antipsychotics. In contrast, there is a fair chance of healthy outcomes in infants exposed to olanzapine during early, late, and throughout pregnancy as has been demonstrated in methodologically sound studies. $^{12}$

Quetiapine : Quetiapine is rated FDA Pregnancy Category C. Preclinical safety data from the Summary of Product Characteristic report no teratogenic effects in animals. In human studies, quetiapine showed the lowest amount of placental passage (mean $=23.8 \%, \mathrm{SD}=11.0$ ) when compared with both FGAs (haloperidol) and SGAs (risperidone and olanzapine). ${ }^{13}$ Moreover, drug maternal serum levels and pharmacokinetic properties do not show relevant changes during pregnancy. ${ }^{14}$ A good number of case reports and a prospective study ${ }^{9}$ vouch for its safety.
Risperidone : Risperidone is rated FDA Pregnancy Category C, and the drug has shown no direct teratogenic effects in animal studies (Janssen drug info 2005). McKenna et al. (2005) ${ }^{9}$ established its safety through a prospective study, confirming earlier reports. In fact, only sporadic clinical observations have described fetal malformations (e.g. anal atresia, corpus callosum agenesis etc) and complicated pregnancy outcomes following in utero exposure to the drug. ${ }^{15,16}$

Ziprasidone : Ziprasidone is rated FDA Pregnancy Category C. In animal studies, ziprasidone demonstrated developmental toxicity, including possible teratogenic effects (mainly represented by ventricular septum defects and kidney malformations), at doses similar to the human therapeutic dose.

Structural/behavioural Teratogenicity: Case reports showing transient unwanted effects on neonatal cardiac rhythm with aripiprazole exposure have been published. Perinatal complications including transient floppy infant syndrome, retinopathy, and severe neonatal hypoxemic encephalopathy have been reported with clozapine exposure. Pinkofsky et al. $(1997)^{17}$ have raised the issue of potential clozapine-induced fetal agranulocytosis. Perinatal complications of various degrees of severity may also occur with risperidone exposure, ranging from withdrawal reactions to seizures.

Gestational Metabolic Complications: Women who become obese prior to pregnancy are more likely to deliver malformed babies than non-obese women; the mechanism underlying such an association may be related to undiagnosed diabetes. ${ }^{18}$ Gestational diabetes has also been associated with an increased risk of developing breast cancer later in the mother's life. Until now, amisulpride, aripiprazole, quetiapine, sertindole, and ziprasidone have not been associated with occurrence of gestational metabolic complications, whereas a single case of gestational diabetes has been reported during therapy with risperidone. ${ }^{15}$ 


\section{FGAS}

Haloperidol : Haloperidol is rated FDA Pregnancy Category C. In animal studies, haloperidol rarely induced fetal malformations. In human beings, the amount of placental passage shown by the drug is $65.5 \% 640.3 \%$ (SD). ${ }^{11}$ Information describing congenital anomalies (most frequently, limb defects; also micropthalmia, bullous emphysema, cystic hygroma etc) in neonates born to mothers who took haloperidol while pregnant are controversial. A multicentric, prospective, controlled cohort study ${ }^{19}$ showed that babies exposed in utero to haloperidol showed congenital malformation in rates within the expected baseline risk for the general population. However, because of the small sample size and the ratio between exposed and unexposed subjects, the study had a detection power of $80 \%$ to identify a 2.9-fold increase in the overall rate of major malformations (with 95\% confidence interval).

Penfluridol and Pimozide: Penfluridol and pimozide are both rated FDA Pregnancy Category C. The study by Diav-Citrin et al. $(2005)^{19}$ identified a small number of pregnancies exposed to penfluridol. One case of fetal malformation was recorded, whereas no cases of birth defects have been reported in anecdotal description of human pregnancies exposed to pimozide. ${ }^{15}$

Flupenthixol, Chlorprothixene, and Zuclopenthixol:Chlorprothixeneandzuclopenthixol are both rated FDA Pregnancy Category $\mathrm{C}$ and the status for FPX has not been established yet. Retrospective assessment of pregnancies by a recent study ${ }^{15}$ showed situs inversus + PDA with FPX exposure, hypospadias plus urinary tract malformations with $\mathrm{ZPX}$ exposure.

Phenothiazines: The teratogenic effect of phenothiazines as a group has been proved in mice and rats..$^{20}$ The amount of placental passage of these drugs is unknown. ${ }^{3}$ In human beings, Favre-Tissot and colleagues (1964) $)^{21}$ investigated the outcomes of a relatively large number of phenothiazine-exposed pregnancies,mostof themexposed tochlorpromazine. Although some cases of fetal major malformations were recorded, the authors concluded that the rate of these anomalies was not statistically different from that shown by unexposed populations. In contrast, a statistically significant increase in the rate of birth defects associated with first trimester exposure to phenothiazines with 3- carbon aliphatic side chain (specifically, chlorpromazine, methotrimeprazine, trimeprazine, and oxomemazine) was demonstrated in some prospective surveys (e.g. Slone et al. 1977) ${ }^{22}$. However, in one of the studies, phenothiazines were also used for controlling threat of abortion. Because early pregnancy loss may be due to an embryo affected by chromosomal or structural anomalies, the reported association between pregnancy exposure to this class of antipsychotics and birth defects seems to be the result rather than the cause of birth defects. The following table discusses the individual phenothiazines.

\begin{tabular}{|l|l|l|}
\hline \multicolumn{1}{|c|}{ Drugs } & \multicolumn{1}{c|}{ Category } & \multicolumn{1}{c|}{ Evidences of harm } \\
\hline CPZ & C & $\begin{array}{l}\text { Neonatal respiratory distress if used at daily doses higher than } 500 \\
\text { mg, fetal malformation, gestational diabetes. Perinatal complications } \\
\text { if used in late pregnancy (case reports mainly). }\end{array}$ \\
\hline PCP & C & Major and minor congenital malformations. \\
\hline TFP & C & Case reports of skeletal and internal deformities. \\
\hline FFZ & Not assigned & Grossly safe \\
\hline THR & Not assigned & EPS in neonates if exposed late; 'risk' of cleft lip/palate \\
\hline $\begin{array}{l}\text { Promethazine, } \\
\text { Perphenazine }\end{array}$ & C & Gestational metabolic complications through sporadic case reports \\
\hline
\end{tabular}




\section{Psychotropic Drugs in Pregnancy}

Perinatal/behavioural teratogenicity : Perinatal complications arising out of late exposure to HPL ranges from withdrawal symptoms to instability of body temperature and those from $\mathrm{CPZ}$ includes extrapyramidal signs, which may persist up to 1 year of age; respiratory distress; seizures; and transient neurodevelopmental delay.

Gestational Metabolic Complications : Although few researches suggest that FGAs may also induce clinically relevant weight gain during long-term therapy until now the number of reports describing FGA-induced gestational metabolic complications is limited.

\section{SSRIS \& SNRIS}

The selective serotonin reuptake inhibitors (SSRIs), particularly fluoxetine, are a medication class that has been well studied in pregnancy and lactation. Multiple studies have shown no teratogenic effects with exposure any time during pregnancy to fluoxetine, fluvoxamine, paroxetine, and sertraline. Nevertheless, SSRIs may cause certain clinical problems. Gestational exposure to SSRIs (fluoxetine, fluvoxamine, paroxetine, and sertraline) late in pregnancy has been found to be associated with an increase in premature delivery, lower birth weight, and lower APGAR scores.

Fluoxetine : Two review-articles ${ }^{23,24}$ analyzed critically the results of the first study on pregnancy outcome following first-trimester exposure to fluoxetine. ${ }^{25}$ A non-statistically significant trend toward an increased rate of spontaneous abortions was observed in 128 mothers who took fluoxetine during early pregnancy compared with non-exposed mothers. It was suggested that maternal depression, rather that maternal treatment, might be associated with a higher rate of pregnancy loss. ${ }^{24}$

Citalopram : Here also a single study ${ }^{26}$ looked for adverse outcome. It evaluated 125 women treated with the drug at least during the first trimester of pregnancy. Pregnant women administered citalopram were matched to a disease matched group of untreated women and a group of women exposed to nonteratogenic agents. This study failed to demonstrate be statistically significant differences in the rate of pregnancy loss between the groups.

Fluvoxamine and Sertraline : Non significant excess of spontaneous abortions.

Paroxetine : Adverse events in neonates associated with third trimester exposure to paroxetine included neonatal symptoms of irritability, jitteriness, constant crying, shivering, eating or sleeping difficulties, gastrointestinal symptoms, and seizures. ${ }^{27,28}$ In a prospective study, paroxetine was associated with a higher rate of neonatal complications (12/55 patients) including respiratory distress $(9 / 55)$, hypoglycemia $(2 / 55)$, and jaundice $(1 / 55)$, all of which resolved within 1 to 2 weeks. ${ }^{28}$

Venlafaxine : A multicenter prospective controlled study suggests that first trimester use does not increase the teratogenic risk..$^{29}$

Duloxetine : Inadequate data for use in pregnancy.

\section{TCAS}

Desipramine (a secondary TCA) is the preferred TCA because it is less anticholinergic and least likely to cause orthostatic hypotension during pregnancy. ${ }^{30}$ Amitriptyline, imipramine, and nortriptyline have received FDA D ratings. Early studies involving all TCAs were suggestive of limb anomalies. The dose of TCAs may need to be increased up to 1.6 times the preconception dose to maintain a therapeutic concentration late in pregnancy. ${ }^{31}$ Anticholinergic effects can cause neonatal toxicity, including symptoms of functional bowel obstruction and urinary retention. TCA withdrawal in neonates has been observed with symptoms of jitteriness, irritability, and, less commonly, seizures, although such withdrawal seizures have only been reported with clomipramine. In all these cases, the symptoms have been transient. The landmark neurodevelopmental study of TCAs and SSRIs by Nulman et al. showed no neurobehavioral effects compared with control infants aged 15-71 months. ${ }^{32,33}$ 


\section{MAOIS}

Monoamine oxidase inhibitors (MAOIs) have been used for more than 40 years with limited pregnancy data. Animal studies have reported teratogenic potential from embryonic exposure to MAOIs. Terbutaline sulfate, a drug used to forestall delivery, should be used with caution in combination with an MAOI due to the potential to cause an adrenergic crisis. Due to dietary and medication restrictions, along with the potential to cause hypertensive crises, this class should not be used during pregnancy. ${ }^{31}$

\section{OTHERS}

Bupropion is classified as category B due to no adverse outcomes in animal studies. ${ }^{31} \mathrm{~A}$ recent prospective comparative study of 136 women exposed to bupropion during pregnancy did not show an increase in the rates of major malformations among infants. ${ }^{34}$

Limited data exist on mirtazapine. Animals receiving 17-20 times the maximum recommended human dose of mirtazapine (based on $\mathrm{mg} / \mathrm{m} 2$ ) did not show teratogenic effects, but did have an increase in pup death and a decrease in the birth weight. A recent comparative meta-analysis of mothers who took newer antidepressants during the first trimester of pregnancy $(\mathrm{N}=1774)$ did not show higher rates of major malformations in infants of mothers exposed to these antidepressants compared with infants of nonexposed mothers. ${ }^{35}$ The antidepressants examined included mirtazapine, along with citalopram, escitalopram, fluoxetine, fluvoxamine, paroxetine, sertraline, reboxetine, venlafaxine, nefazodone, trazodone, and bupropion.

\section{MOOD STABILIZERS}

Lithium: Lithium's teratogenicity has been overestimated in the past. ${ }^{36}$ Previous studies indicated a 400-fold increase in congenital heart malformations, particularly Ebstein's anomaly. Subsequent investigations have indicated that the risk of Ebstein's anomaly with lithium treatment is 20-40 times higher than the rate in the general population, in which the rate of Ebstein's anomaly is $1 / 20,000 .{ }^{37}$ Although lithium does present these risks for adverse effects, the risks are significantly lower than previously believed.

Lithium has been known to cause "floppy baby syndrome," characterized bycyanosis and hypotonia. Case reports concerning late gestational exposure describe fetal cardiac arrhythmia), hypoglycemia, nephrogenic diabetes insipidus, reversible thyroid changes, polyhydraminos, infants large for gestational age, flaccidity, lethargy, and poor sucking reflex. A 5-year follow-up of 60 school-age children exposed to lithium during gestation found no overt evidence of neurobehavioral changes. ${ }^{38}$ Lithium levels in the umbilical cord have been found to be equivalent to maternal blood levels. ${ }^{39}$

Lithium should be tapered prior to conception in patients with mild illnesses; in more severe cases, patients should be counseled either to avoid lithium during the first trimester or use the lowest amount possiblein divided dose. ${ }^{31}$ Lithium recommendations also include a fetal echocardiogram with high resolution ultrasound between 16 to 18 weeks gestation, a neonatal electrocardiogram, and monitoring of the infant for 10 days after birth for lithium toxicity. ${ }^{40}$ Lithium levels should be monitored weekly in the last month of pregnancy. ${ }^{40}$ In the third trimester, renal excretion may increase by $30 \%$ to $50 \%$, requiring an increase in the lithium dose. ${ }^{41}$ Therefore, to avoid neonatal toxicity, it is recommended to either discontinue lithium 2-3 days before delivery or decrease the dose by $25 \%$. $^{37,42}$

SV: SV is considered a teratogen and is associated with numerous malformations including neural tube defects with a prevalence 10-20 times greater than in the general population, craniofacial anomalies, limb abnormalities, cardiovascular anomalies, genitourinary malformations, and low birth weight. The risk of fetal malformations increases with anticonvulsant polypharmacy and in mothers who exceed $1000 \mathrm{mg}$ SV per day. ${ }^{31}$

If used during pregnancy, folate supplements should be given due to the antagonistic effect of SV 
on folate and the association between neural tube defects and folate deficiency. ${ }^{31}$ While a matter of some controversy, pre-conception folate may help prevent these defects. ${ }^{43}$

Most neurobehavioral studies on SV have been done in women with epilepsy, so that it is difficult to discriminate the effects of prenatal anticonvulsant exposure from prenatal exposure to maternal epilepsy. ${ }^{31}$ Retrospective reports indicate developmental delay and mental retardation in children exposed to SV monotherapy prenatally. ${ }^{44,45}$

CBZ : Carbamazepine has teratogenic risks similar to $\mathrm{SV}$, but these are less frequent and severe. ${ }^{31}$ Teratogenic effects include neural tube defects, cleft palate, cardiovascular abnormalities, and urinary tract anomalies. Fetal carbamazepine syndrome is manifested by a short nose, long philtrum, epicanthal folds, hypertelorism, upslanting palpebral fissures, and fingernail hypoplasia. CBZ's teratogenic potential is increased when it is given in combination with SV. Maternal serum alpha fetoprotein levels, fetal echocardiogram and level 2 ultrasound at 1618 weeks gestation, and folate supplementation (4-5 mg per day) are recommended. ${ }^{31} \mathrm{CBZ}$ has been linked to reductions in birth weight (approx 250 gm) decreased mean head circumference, transient hepatic toxicity, and fetal vitamin K deficiency. Oral vitamin $\mathrm{K}$ (20 $\mathrm{mg} /$ day) is therefore recommended in the last month of pregnancy, and the infant should receive $1 \mathrm{mg}$ IM of vitamin $\mathrm{K}$ after in utero CBZ exposure. ${ }^{36}$

LTG \& OxCBZ : Data on lamotrigine (LTG) and oxcarbazepine are limited and there are no neurobehavioral data. ${ }^{31}$ Oxcarbazepine has been used in Europe for more than a decade and retrospective studies on 12 patients with first trimester exposure have found no congenital anomalies. ${ }^{46}$ Folate supplementation should be given until the teratogenic risks are further clarified. ${ }^{31}$

The Lamotrigine Pregnancy Registry indicates less than a $2 \%$ risk for fetal malformation with first trimester exposure to LTG based on a total of 1081 registered cases and 693 obtained birth outcomes (as of Sept 2003). ${ }^{31,36}$ Routine folate supplementation (4-5 $\mathrm{mg} /$ day) is recommended in women of reproductive age (pregnant or not) (Newport et al. 2001). LTG clearance progressively increased $(\mathrm{N}=14)$ until 32 weeks, when it reached a peak of $>330 \%$ of baseline and then began to decline. ${ }^{47}$

\section{BZDS}

A pooled meta-analysis found the risk of oral clefts, which is $6 / 10,000$ in the general population, increased only $0.01 \%$ to $7 / 10,000$ with first trimester exposure to BZDs. ${ }^{48}$ A recent meta-analysis that reviewed data from 1,400 studies showed no risk of major malformations based on cohort studies, but did find an association between BZD exposure and development of major malformations or oral cleft when case control studies were analyzed. ${ }^{49}$ Due to the conflicting data, it is recommended that BZDs be avoided during pregnancy, particularly in the first trimester, and that a level 2 ultrasound be obtained during pregnancy to rule out visible forms of oral cleft. ${ }^{49}$

BZDs have been shown to cause neonatal toxicity and withdrawal symptoms. Floppy infant syndrome includes hypothermia, lethargy, poor respiratory effort, and feeding difficulties after maternal use of BZDs. Neonatal withdrawal syndromes from alprazolam, chlordiazepoxide, and diazepam have been characterized by restlessness, hypertonia, hyperreflexia, tremulousness, apnea, diarrhea, and vomiting. These symptoms have been reported as long as 3 months after delivery. Fetal rates of benzodiazepine metabolism are considerably slower than in adults. The fetal-maternal ratio of diazepam is greater than 1 at delivery, and levels of lorazepam have been detectable in infants 8 days after delivery. ${ }^{50}$ Neonates metabolize medications more slowly; potentially resulting in toxic serum levels. Thus, long-term use of BZDs by a breast-feeding mother could potentially lead to a buildup of the drug in the infant. If an infant experiences sedation or other signs of BZD toxicity, breast-feeding should be discontinued. ${ }^{31}$ 
Psychotropic Drugs in Pregnancy

The use of long-acting benzodiazepines, such as diazepam and clobazam, is contraindicated in breastfeeding mothers and all other BZDs are to be used with caution. If a benzodiazepine is needed during breastfeeding, then a short-acting one, such as midazolam, oxazepam, pinazepam, or lormetazepam, should be used. However Zaleplon, Zolpidem and Zopiclone can be safely used..$^{51}$

\section{OTHER DRUGS}

\section{Disulfiram : Phocomelia}

Methadone : Protracted opioid withdrawal

Clonidine : Behavioural teratogen.

ECT : Vaginal bleeding, PROM, premature labour.

Methylphenidate : Methylphenidate shows an $\mathrm{M} / \mathrm{P}$ that varies from 1.1 to 2.7 and a relative infant dosage that is $0.2 \%$ of the maternal dosage; however, the available information is too scant to permit an evaluation of the safety profile of the drug.

\section{CONCLUSION}

Eventually it is a clinical decision whether or not to change or stop the ongoing psychotropic during pregnancy. Besides risk and benefit analysis, patients' choice, after providing all the detailed relevant information is also important.

\section{REFERENCES}

1. Odegård O. Fertility of psychiatric first admissions in Norway 1936-1975. Acta Psychiatr Scand. 1980 Sep; 62(3) : 212-20.

2. Miller WH Jr, Bloom JD, Resnick MP. Hosp Community Psychiatry. 1992 Sep; 43(9) : 942-3. Prenatal care for pregnant chronic mentally ill patients.

3. Gentile S. Infant safety with antipsychotic therapy in breastfeeding: a systematic review. J Clin Psychiatry. 2008 Apr; 69(4) : 666-73.

4. Grof P, Robbins W, Alda M, Berghoefer A, Vojtechovsky M, Nilsson A, Robertson C. Protective effect of pregnancy in women with lithium-responsive bipolar disorder. J Affect Disord. 2000 Dec; 61(1-2) : 31-9.

5. Freeman MP, Smith KW, Freeman SA, McElroy SL, Kmetz GE, Wright R, Keck PE Jr. The impact of reproductive events on the course of bipolar disorder in women. J Clin Psychiatry. 2002 Apr; 63(4) : 284-7.
6. Mendhekar DN, Sunder KR, Andrade C. Aripiprazole use in a pregnant schizoaffective woman. Bipolar Disord. 2006 Jun; 8(3) : 299-300.

7. Mendhekar DN, Sharma JB, Srilakshmi P. Use of aripiprazole during late pregnancy in a woman with psychotic illness. Ann Pharmacother. 2006 Mar; 40(3) : 575. Epub 2006 Feb 7.

8. Kłys M, Rojek S, Rzepecka-Woźniak E. Neonatal death following clozapine self-poisoning in late pregnancy : an unusual case report. Forensic Sci Int. 2007 Aug 24; 171(1) : e5-e10.

9. McKenna K, Koren G, Tetelbaum M, Wilton L, Shakir S, Diav-Citrin O, Levinson A, Zipursky RB, Einarson A. Pregnancy outcome of women using atypical antipsychotic drugs : a prospective comparative study. J Clin Psychiatry. 2005 Apr; 66(4) : 444-9; quiz 546.

10. Arora M, Praharaj SK. Meningocele and ankyloblepharon following in utero exposure to olanzapine. Eur Psychiatry. 2006 Jul; 21(5) : 345-6.

11. Newport DJ, Calamaras MR, DeVane CL, Donovan J, Beach AJ, Winn S, Knight BT, Gibson BB, Viguera AC, Owens MJ, Nemeroff CB, Stowe ZN. Atypical antipsychotic administration during late pregnancy: placental passage and obstetrical outcomes. Am J Psychiatry. 2007 Aug; 164(8) : 1214-20.

12. Brunner E, Falk DM, Jones M, Dey DK, Shatapathy CC. Olanzapine in pregnancy and breastfeeding: a review of data from global safety surveillance. BMC Pharmacol Toxicol. 2013 Aug 1;14:38.

13. Friedman JH. Atypical antipsychotics in the EPS-vulnerable patient. Psychoneuroendocrinology. 2003 Jan; 28 Suppl 1 : 39-51.

14. Klier CM, Mossaheb N, Saria A, Schloegelhofer M, Zernig G. Pharmacokinetics and elimination of quetiapine, venlafaxine, and trazodone during pregnancy and postpartum. J Clin Psychopharmacol. 2007 Dec; 27(6) : 720-2.

15. Reis M, Källén B. Maternal use of antipsychotics in early pregnancy and delivery outcome. J Clin Psychopharmacol. 2008 Jun; 28(3) : 279-88.

16. McCauley-Elsom $\mathrm{K}$, Kulkarni J. Managing psychosis in pregnancy. Aust N Z J Psychiatry. 2007 Mar; 41(3) : 289-92.

17. Pinkofsky HB. Psychosis during pregnancy : treatment considerations. Ann Clin Psychiatry. 1997 Sep; 9(3) : 175-9.

18. Waller DK, Shaw GM, Rasmussen SA, Hobbs CA, Canfield MA, Siega-Riz AM, Gallaway MS, Correa A; National Birth Defects Prevention Study. Prepregnancy obesity as a risk factor for structural birth defects. Arch Pediatr Adolesc Med. 2007 Aug; 161(8) : 745-50.

19. Diav-Citrin O, Shechtman S, Ornoy S, Arnon J, Schaefer C, Garbis H, Clementi M, Ornoy A. Safety of haloperidol and penfluridol in pregnancy: a multicenter, prospective, controlled study. J Clin Psychiatry. 2005 Mar; 66(3) : 317-22.

20. Szabo KT, Brent RL. Letter: Species differences in experimental teratogenesis by tranquillising agents. Lancet. 1974 Mar 30; 1(7857) : 565.

21. Favre-Tissot M, Broussolle P, Robert JM, Dumont L. Psychopharmacology and teratogenesis; summary of a 


\section{Psychotropic Drugs in Pregnancy}

preliminary clinical survey. Ann Med Psychol (Paris). 1964 Mar; 122 : 389-400.

22. Slone D, Siskind V, Heinonen OP, Monson RR, Kaufman DW, Shapiro S. Antenatal exposure to the phenothiazines in relation to congenital malformations, perinatal mortality rate, birth weight, and intelligence quotient score. Am J Obstet Gynecol. 1977 Jul 1; 128(5) : 486-8.

23. Loebstein R, Koren G. Pregnancy outcome and neurodevelopment of children exposed in utero to psychoactive drugs: the Motherisk experience. J Psychiatry Neurosci. 1997 May; 22(3) : 192-6.

24. Koren G, Pastuszak A, Ito S. Drugs in pregnancy. N Engl J Med. 1998 Apr 16; 338(16) : 1128-37.

25. Pastuszak A, Schick-Boschetto B, Zuber C, et al. Pregnancy outcome following first-trimester exposure to fluoxetine (Prozac). JAMA. 1993 May 5; 269(17) : 2246-8.

26. Sivojelezova A1, Shuhaiber S, Sarkissian L, Einarson A, Koren G. Citalopram use in pregnancy: prospective comparative evaluation of pregnancy and fetal outcome. Am J Obstet Gynecol. 2005 Dec; 193(6) : 2004-9.

27. Stiskal JA1, Kulin N, Koren G, Ho T, Ito S. Neonatal paroxetine withdrawal syndrome. Arch Dis Child Fetal Neonatal Ed. 2001 Mar; 84(2) : F134-5.

28. Costei AM, Kozer E, Ho T, Ito S, Koren G. Perinatal outcome following third trimester exposure to paroxetine. Arch Pediatr Adolesc Med. 2002 Nov; 156(11) : 1129-32.

29. Einarson A1, Fatoye B, Sarkar M, Lavigne SV, Brochu J, Chambers C, Mastroiacovo P, Addis A, Matsui D, Schuler L, Einarson TR, Koren G. Pregnancy outcome following gestational exposure to venlafaxine : a multicenter prospective controlled study. Am J Psychiatry. 2001 Oct; 158(10) : 1728-30.

30. Nonacs R, Cohen LS. Assessment and treatment of depression during pregnancy : an update. Psychiatr Clin North Am. 2003 Sep; 26(3) : 547-62.

31. Newport DJ, Wilcox MM, Stowe ZN. Antidepressants during pregnancy and lactation: defining exposure and treatment issues. Semin Perinatol. 2001 Jun; 25(3) : 177-90.

32. Nulman I, Rovet J, Stewart DE, Wolpin J, Pace-Asciak P, Shuhaiber S, Koren G. Child development following exposure to tricyclic antidepressants or fluoxetine throughout fetal life : a prospective, controlled study. Am J Psychiatry. 2002 Nov; 159(11) : 1889-95.

33. Nulman I, Rovet J, Stewart DE, Wolpin J, Gardner HA, Theis JG, Kulin N, Koren G. Neurodevelopment of children exposed in utero to antidepressant drugs. N Engl J Med. 1997 Jan 23; 336(4) : 258-62.

34. Chun-Fai-Chan B1, Koren G, Fayez I, Kalra S, Voyer-Lavigne S, Boshier A, Shakir S, Einarson A. Pregnancy outcome of women exposed to bupropion during pregnancy : a prospective comparative study. Am J Obstet Gynecol. 2005 Mar; 192(3) : 932-6.

35. Einarson TR, Einarson A. Newer antidepressants in pregnancy and rates of major malformations : a meta-analysis of prospective comparative studies. Pharmacoepidemiol Drug Saf. 2005 Dec; 14(12) :823-7.
36. Yonkers KA, Wisner KL, Stowe Z, Leibenluft E, Cohen L, Miller L, Manber R, Viguera A, Suppes T, Altshuler L. Management of bipolar disorder during pregnancy and the postpartum period. Am J Psychiatry. 2004 Apr; 161(4) : 608-20.

37. Cohen LS, Friedman JM, Jefferson JW, Johnson EM, Weiner ML. A reevaluation of risk of in utero exposure to lithium. JAMA. 1994 Jan 12; 271(2) : 146-50.

38. Schou M. What happened later to the lithium babies? A follow-up study of children born without malformations. Acta Psychiatr Scand. 1976 Sep; 54(3) : 193-7.

39. Schou M, Amdisen A, Steenstrup OR. Lithium and pregnancy. II. Hazards to women given lithium during pregnancy and delivery. Br Med J. 1973 Apr 21; 2(5859) : 137-8.

40. Pinelli JM, Symington AJ, Cunningham KA, Paes BA. Case report and review of the perinatal implications of maternal lithium use. Am J Obstet Gynecol. 2002 Jul; 187(1) : 245-9.

41. Schou M. Treating recurrent affective disorders during and after pregnancy. What can be taken safely? Drug Saf. 1998 Feb; 18(2) : 143-52.

42. Schou M. Lithium treatment during pregnancy, delivery, and lactation : an update. J Clin Psychiatry. 1990 Oct; 51(10) : 410-3.

43. Jain AE, Lacy T. Psychotropic drugs in pregnancy and lactation. J Psychiatr Pract. 2005 May; 11(3) : 177-91.

44. Moore SJ, Turnpenny P, Quinn A, Glover S, Lloyd DJ, Montgomery T, Dean JC. A clinical study of 57 children with fetal anticonvulsant syndromes. J Med Genet. 2000 Jul; 37(7) : 489-97.

45. Kozma C. Valproic acid embryopathy: report of two siblings with further expansion of the phenotypic abnormalities and a review of the literature. Am J Med Genet. 2001 Jan 15; 98(2) : 168-75.

46. Friis ML1, Kristensen O, Boas J, et al. Therapeutic experiences with 947 epileptic out-patients in oxcarbazepine treatment. Acta Neurol Scand. 1993 Mar; 87(3) : 224-7.

47. Pennell PB, Newport DJ, Stowe ZN, Helmers SL, Montgomery JQ, Henry TR. The impact of pregnancy and childbirth on the metabolism of lamotrigine. Neurology. 2004 Jan 27; 62(2) : 292-5.

48. Altshuler LL, Cohen L, Szuba MP, Burt VK, Gitlin M, Mintz J. Pharmacologic management of psychiatric illness during pregnancy : dilemmas and guidelines. Am J Psychiatry. 1996 May; 153(5) : 592-606.

49. Dolovich LR, Addis A, Vaillancourt JM, Power JD, Koren G, Einarson TR. Benzodiazepine use in pregnancy and major malformations or oral cleft : meta-analysis of cohort and case-control studies. BMJ. 1998 Sep 26; 317(7162) : 839-43.

50. Whitelaw AG, Cummings AJ, McFadyen IR. Effect of maternal lorazepam on the neonate. Br Med J (Clin Res Ed). 1981 Apr 4;282(6270):1106-8.

51. Fortinguerra F, Clavenna A, Bonati M. Psychotropic drug use during breastfeeding : a review of the evidence. Pediatrics. 2009 Oct; 124(4) : e547-56. 